\title{
Screening of Red Algae Filaments As a Potential Alternative Source of Eicosapentaenoic Acid
}

\author{
Chih-Yu Chen ${ }^{*, 1}$ and Hong-Nong $\mathrm{Chou}^{2}$ \\ ${ }^{1}$ Science and Technology Information Center, National Science Council, 16F, No. 106, Hoping E. RD., Sec. 2, Taipei, Taiwan \\ (106-36), Republic of China \\ Institute of Fisheries Science, National Taiwan University, Taipei, Taiwan 10617, Republic of China
}

\begin{abstract}
Lipids were extracted by a supercritical fluid extraction method from 10 species of filamentous red algae obtained from culture collections and their fatty acid compositions were determined. The fatty acid

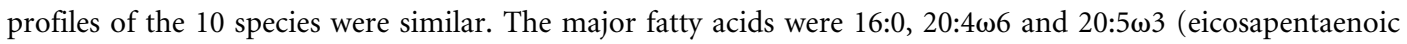
acid, EPA), which amounted to over $70 \%$ of the total fatty acids. The highest EPA content $(29.8 \mathrm{mg} / \mathrm{L})$, as a percentage of total fatty acids, was produced by Liagora boergesenii filaments, which has good potential for EPA mass production in pilot plants.
\end{abstract}

Key words: red algae, supercritical fluid extraction, eicosapentaenoic acid.

\section{INTRODUCTION}

The mass production of omega-3 ( $\omega 3)$ polyunsaturated fatty acids (PUFAs) is being studied because of their role in human health (Grima et al., 1995; Reis et al., 1996). The therapeutic value of PUFAs, especially eicosapentaenoic acid (EPA), has been shown in the reduction of blood cholesterol (Bonaa et al., 1990), in the prevention of bloodplatelet aggregation, and as a protection against cardiovascular and coronary heart diseases (Simopoulos, 1986). Fish oil is generally the major source of PUFAs, but the product has a fishlike smell (Ackman et al., 1988). Several publications have pointed out the feasibility of PUFA production from microbial sources, with special emphasis on fungi (Kennedy et al., 1993) and microalgae (Bajpai and Bajpai, 1993). Although the microalgae have several advantages

Received June 27, 2001; accepted October 16, 2001

${ }^{\star}$ Corresponding author: telephone 886-2-27377729; fax 886-2-27377448; e-mail cychen@mail.stic.gov.tw over fish oil (Reis et al., 1994), their production cost is high. Red algae contain high levels of PUFAs; the PUFA concentration is similar to that of fish oil and microalgae (Araki et al., 1986; Lu, 1992). Filaments of red algae in the conchocelis phase (2n) have the benefits of a faster growth rate, easy culture, and lower production cost (Hung, 1994). Furthermore, the PUFA content of the conchocelis is higher than that of the thalli (Lu, 1992), and our laboratory has set up an analytical-scale system to culture the filaments of this red alga.

In early extraction methods, removal of the organic solvent is difficult. More recently, supercritical fluid extraction (SFE) has been investigated as a good technique for the determination of fat in vegetable oil and meats (Walker et al., 1994; Taylor et al., 1997). That SFE has the advantages of savings in labor, operational costs, and laboratory space, waste minimization, nontoxicity, and increased selectivity over traditional extraction methods is generally true (Samyudia et al., 1996; Lehotay, 1997). However, there are no reports regarding the use of the SFE technique in algae. In 
this study, we determined the fatty acid composition of red algal filaments and evaluated their potential as EPA producers.

\section{Materials and Methods}

The algal species analyzed were Bangia atropurpurea, Porphyra angusta, Porphyra dentata (Bangiaceae); Helminthocladia australis, Liagora orientalis, Liagora boergesenii (Helminthocladiaceae); Scinaia monoliformis, Galaxaura cylindrica (Chaetangiaceae); Grateloupia filicina, Halymenia ceylanica (Grateloupiaceae). The filamentous plants (conchocelis) were originally germinated from a single carpospore of red algae using a method similar to that for Porphyra species (Chiang and Wang, 1980). Filaments of red algae were propagated by fragmentation and grown into colonies of filamentous clusters in SWM-III medium (Chen et al., 1969). The conchocelis was maintained at $20^{\circ} \mathrm{C}$ under fluorescent light (2000 lux) with a light-dark regimen (12:12 h). Mass cultures of the filaments were maintained in $20 \mathrm{~L}$ of polycarbonate (Nalgene Labware, Rochester, N.Y.) with continuous aeration by aquarium air pumps.

After 2 weeks of incubation, algae were harvested with a plankton net. Excess water was removed by filtration on a Buchner funnel using suction. Wet filamentous plants were lyophilized and then ground in a mortar. Filamentous fragments were extracted by high-pressure soxhlet extractor (J $\&$ W Scientific Co.). The SFE process was completed under $500 \mathrm{psi}, 55^{\circ} \mathrm{C}$, for 3 hours; the condenser temperature was $15^{\circ} \mathrm{C}$; and the supercritical solvent was $\mathrm{CO}_{2}$. The extract was dissolved in a small volume of chloroform and then methylated by diazald (Chen, 1993). Fatty acids were determinated as methyl esters using gas chromatography-mass spectroscopy. Pentadecanoic acid (Supelco) was used as a standard. Fatty acid methyl esters (FAMEs) were identified by comparison of retention times with known standards (FAME-1, Supelco). The extract was analyzed using HP 5890 series II GC and HP 5971 MSD. The GC-MS analysis conditions are summarized in Table 1.

\section{Results}

All of the 10 red algae species grew rapidly under laboratory conditions and reached maximum growth after 10 to 14 days, the biomass increased about 10 to 12 fold (10 $\pm 2 \mathrm{~g}$ wet $\mathrm{wt} / \mathrm{L}$ and $2.12 \pm 0.34 \mathrm{~g}$ dry $\mathrm{wt} / \mathrm{L}$ ). Liagora boergesenii only required a 10-day cultivation period and yielded the highest cell mass ( $12.0 \mathrm{~g}$ wet $\mathrm{wt} / \mathrm{L}$ ). The crude lipid contents
Table 1. Gas Chromatography-Mass Spectroscopy Analysis Conditions

Injection mode: Split (1:27)

Injection amount: $0.5 \mu \mathrm{l}$

Injection temperature: $250^{\circ} \mathrm{C}$

Column: Supelco capillary column (\#2330) $(30 \mathrm{~m} \times 0.25 \mathrm{id})$

Column temperature: $50^{\circ} \mathrm{C}(1 \mathrm{~min}$ wait $) \rightarrow 20^{\circ} \mathrm{C} / \mathrm{min} \rightarrow 140^{\circ} \mathrm{C}$

(7 min wait) $\rightarrow 3^{\circ} \mathrm{C} / \mathrm{min} \rightarrow 180^{\circ} \mathrm{C} \rightarrow 5^{\circ} \mathrm{C} / \mathrm{min} \rightarrow 220^{\circ} \mathrm{C}$

(4 min wait) $\rightarrow$ end

Carrier gas: $\mathrm{He}$

Flow rate: $25 \mathrm{~cm} / \mathrm{s}$

Detector temperature: $280^{\circ} \mathrm{C}$

Table 2. Crude Lipid Contents from Selected Red Algae Filaments (mean $\pm \mathrm{SE}, n=2$ )

Extractable crude lipid

Sample name in dry mass base (\% wt/wt)

Liagora boergesenii

$21.5 \pm 0.5$

Grateloupia filicina

$13.6 \pm 0.2$

Scinaia monoliformis

$17.0 \pm 0.4$

Helminthocladia australis

$19.7 \pm 0.3$

Galaxaura cylindrica

$19.8 \pm 0.4$

Halymenia ceylanica

$18.8 \pm 0.3$

Liagora orientalis

$17.6 \pm 0.4$

Porphyra angusta

$12.4 \pm 0.1$

Porphyra dentata

$11.2 \pm 0.1$

Bangia atropurpurea

$13.3 \pm 0.1$

of the species are presented in Table 2. Liagora boergesenii showed a significantly higher value $(21.5 \% \pm 0.5 \%, 2.58$ $\mathrm{g} / \mathrm{L}$ ) (analysis of variance [ANOVA], $P<0.05$ ) than the others. The value for Galaxaura cylindrica $(19.8 \% \pm 0.4 \%)$ was a little lower than that for Liagora boergesenii, but was higher than those for other red algae filaments. The extraction rate of crude lipid by the SFE method (11.2\%-21.5\%) was significantly higher than that obtained using organic solvents (i.e., $\mathrm{MeOH}_{-} \mathrm{CHCl}_{3}$ [2:], 7.5-15.3\%; ANOVA, $P<$ 0.05) ( $\mathrm{Lu}, 1992)$.

The fatty acid compositions of 10 red algae filaments are shown in Table 3. The major fatty acids were 16:0, $20: 4 \omega 6$, and 20:5 33 (EPA), which amounted to over $70 \%$ of the total fatty acids. Furthermore, Bangia atropurpurea showed the highest content of PUFA (62.6\%), and the $\Sigma \omega 3$ / $\Sigma \omega 6$ value of Liagora boergesenii (2.40) was significantly 


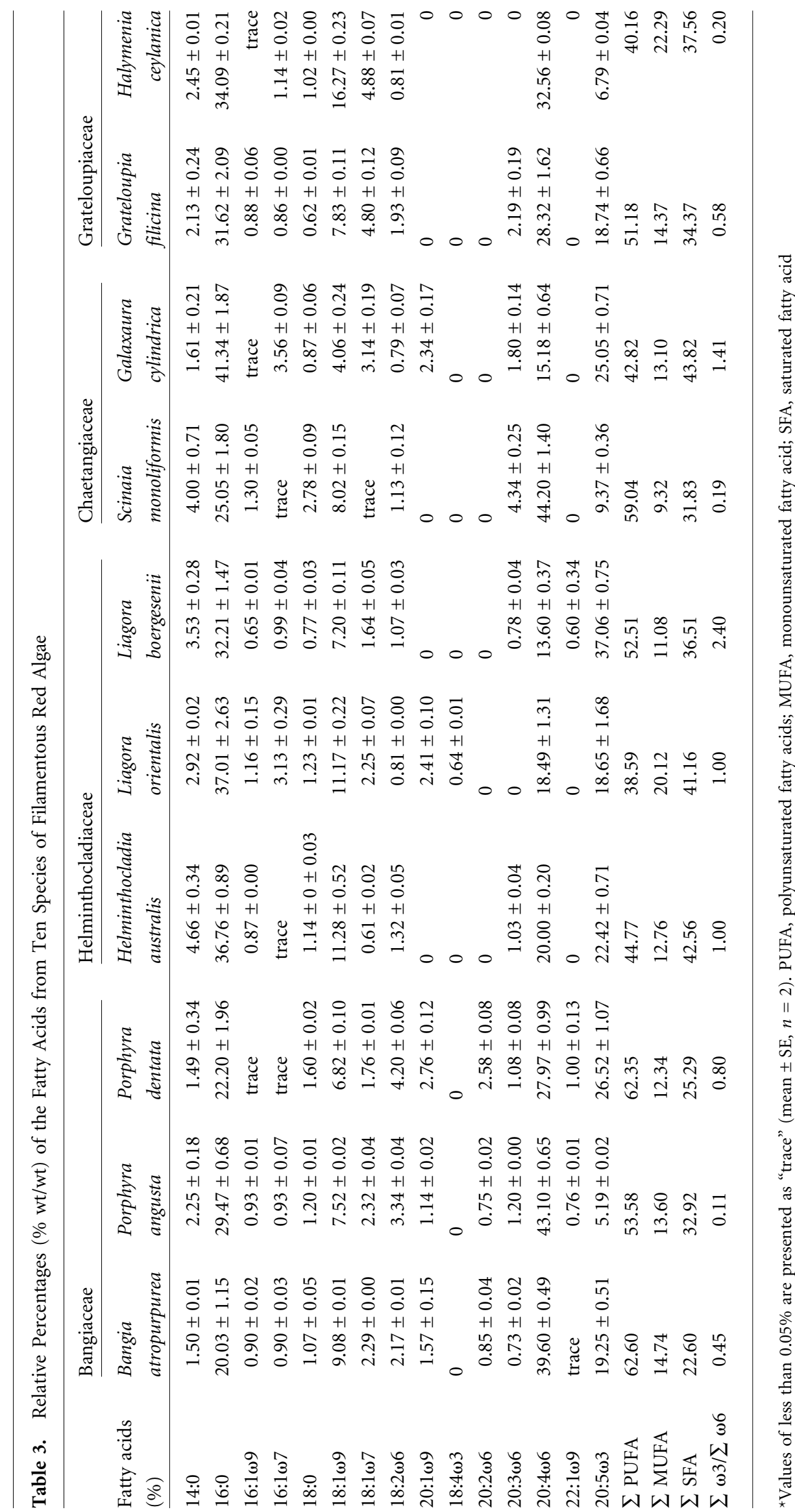


higher than that of other algal samples (ANOVA, $P<0.05$ ). Liagora boergesenii filaments also contained the highest percentage of EPA $(37.06 \%)$ relative to the other red algae samples (ANOVA, $P<0.05$ ). However, 22:6w3 (docosahexaenoic acid, DHA) was not found in all red algae samples. Because DHA is considered to have some different nutritional and pharmacologic effects from EPA, the use of EPAproducing cultures that essentially lack other long-chain PUFAs has the potential to reduce the substantial problems of EPA recovery in downstream processing. Bangia atropurpurea showed the highest total fatty acid content among the 10 samples. Liagora boergesenii had the highest concentration of EPA (6.78 mg/100 mg crude lipid); that is, the EPA content was $29.8 \mathrm{mg} / \mathrm{L}$. This EPA content is higher than that of fish oil and microalgae (Ackman et al., 1988; Grima et al., 1995).

In conclusion, Liagora boergesenii could be used for EPA mass production in a pilot plant, since it shows rapid growth rate and high lipid and EPA content. Furthermore, filamentous red algae will increase EPA content under higher light intensity (Lu, 1992). We are now optimizing the culture conditions for increased EPA production and also the SFE control strategies for highly efficient extraction.

\section{ACKNOWLEDGMENTS}

We thank Dr. Y.M. Chiang for supplying red algae "conchocelis" stock culture. This work was supported by grants from the National Science Council (NSC-83-0209-B-002179) awarded to H.N. Chou.

\section{REFERENCES}

Ackman, R.G., Ratnayake, W.M.N., and Olson, B. (1988). The "basic" fatty acid composition of Atlantic fish oils: potential similarities useful for enrichment of polyunsaturated fatty acids by urea complexation. J Am Oil Chem Soc 65:136-138.

Araki, S., Sakurai, T., Omata, T., Kawaguchi, A., and Murata, N. (1986). Lipid and fatty acid composition in the red alga Porphyra yezoensis. Jpn Phycol 34:94-100.

Bajpai, P., and Bajpai, P.K. (1993). Eicosapentaenoic acid (EPA) production from microorganisms: a review. J Biotechnol 30:161-183.

Bonaa, K.H., Bjerve, K.S., Straume, B., Gram, I.T., and Thelle, D. (1990). Effect of eicosapentaenoic and docosahexaenoic acids on blood pressure in hypertension: a population-based intervention trial from the Tromso study. N Engl J Med 322:795-801.

Chen, C.Y. (1993). Studies on the essential oils in some Formosan seaweeds. Master's thesis, National Taiwan University, Taipei, 16-24.
Chen, L.C.M., Edelstein, T. and McLachlan, J. (1969). Bonnemaisonia hamifera in nature and in culture. J Phycol 5:211-220.

Chiang, Y.M., and Wang, J.C. (1980). A study on the production of conchosporangia in the conchocelis phase of Porphyra angusta Okamura et Ueda. Phycologia 19:20-24.

Grima, E.M., Perez, J.A.S., Camacho, F.G., Medina, A.R., Gimenez, A.G., and Alonso, D.L. (1995). The production of polyunsaturated fatty acids by microalgae: from strain selection to product purification. Proc Biochem 30:711-719.

Hung, Y.P. (1994). The influence of temperature and light on the composition of photosynthetic pigments in the conchocelis of Porphyra angusta Ueda. Master's thesis, National Chung Hsing University, Taipei, 10-26.

Kennedy, M.J., Sarah, L.R., and Davis, R.J. (1993). Fatty acid production characteristics of fungi with particular emphasis on gamma linolenic acid production. Biotechnol Bioengng 42:625-634.

Lehotay, S.J. (1997). Supercritical fluid extraction of pesticides in foods. J Chromatogr A 785:289-312.

Lu, C.K. (1992). Study on fatty acid content and chemical composition of Porphyra spp. and Bangia atropurpurea. Master's thesis, National Taiwan University, Taipei, 21-35.

Reis, A., Gouveia, L., Veloso, V., Fernandes, H.L., Empis, J.A., and Novais, J.M. (1994). Eicosapentaenoic acid production by the microalga Phaeodactylum tricornutum using continuous culture. In: Progress in Biotechnology, Alberghina, L., Frontali, L., and Sensi, P., (ed.). Amsterdam: Elsevier, 9:1121-1124.

Reis, A., Gouveia, L., Veloso, V., Fernandes, H.L., Empis, J.A., and Novais, J.M. (1996). Eicosapentaenoic acid-rich biomass production by the microalga Phaeodactylum tricornutum in a continuousflow reactor. Bioreso Technol 55:83-88.

Samyudia, Y., Lee, P.L., and Cameron, I.T. (1996). Control strategies for a supercritical fluid extraction process. Chem Engng Sci 51:769-787.

Simopoulos, A.P. (1986). Historical perspective, conference conclusions and recommendations, and actions by federal agencies. In: Health Effects of Polyunsaturated Fatty Acids in Seafoods, Simopoulos, A.P., Kifer, R.R., and Martin, R.E. (eds.). Orlando, Fla.: Academic Press, 3-29.

Taylor, S.L., Eller, F.J., and King, J.W. (1997). A comparison of oil and fat content in oilseeds and ground beef-using supercritical fluid extraction and related analytical techniques. Food Res Int 30:365-370.

Walker, D.F.G., Bartle, K.D., and Clifford, A.A. (1994). Determination of the oil content of rapeseed by supercritical fluid extraction. Analyst 119:1471-1474. 